\title{
Optimised Methods for Quantitative Analysis of Solasodine and its Glycoside Solamargine by High Performance Liquid Chromatography
}

\author{
Sana S. Al-Sinani and Elsadig A. Eltayeb*
}

Department of Biology, College of Science, Sultan Qaboos University, P.O. Box 36, Al-Khoud, 123 Muscat, Sultanate of Oman, ${ }^{\star}$ Email: Eatayeb@squ.edu.om.

\begin{abstract}
Improved and simplified HPLC conditions for the determination and quantification of both the steroidal glycoalkaloid (solamargine) and its aglycone (solasodine) are described. The best isocratic conditions were developed using a $\mathrm{C}_{18}$ column and methanol in combination with an ammonium dihydrogen phosphate buffer. The isocratic conditions were shown to be more reproducible, less time consuming and to give sharper peaks (better separation). The effects of adjusting solvent: buffer ratio, buffer $\mathrm{pH}$ and buffer molarity were evaluated.
\end{abstract}

Keywords: HPLC; Solamargine; Solasodine; Steroidal glycoalkaloids; Aglycone.

الطرق المثلى للتحليل الكمي لمركب السولاسودين والكالويده السكري السولامارجين باستخدام جهاز

كروماتوغرافيا السوائل عالمي ألكفاءة (HPLC)

سناء سالم السناني و الصادق عبدالله الطيب

ملخص: هذه المقالة العلمية تصف طريقة مطورة ومبسطة لتحديد وتقدير كميات مركبين أحدهما من الألكلويدات السكريه وهو

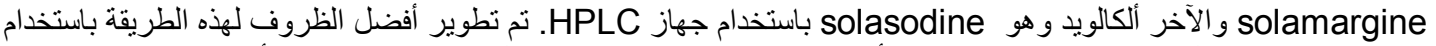
عمود

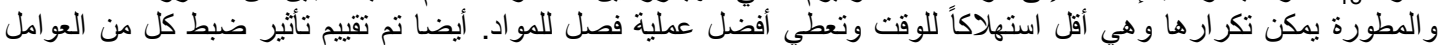

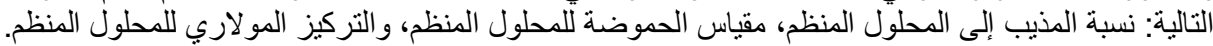

$$
\text { مفتاح الكلمات : جهاز HPLC و سولامارقين ، سو لاسودين الاكلويدات السكرية والاجليكون. }
$$

\section{Introduction}

teroidal glycolakaloids (SGAs) are naturally occurring nitrogen containing toxins found in the Solanaceae family (Carman et al., 1986; Friedman and Dao, 1992). SGAs contain three structural portions: a polar, water soluble sugar moiety with three or four monosaccarides, a non-polar steroid unit and a basic portion with either indolizidine or oxa-azaspirodecane structure (Cherkaoui et al., 2001; Kuronen et al., 1999). UV absorption spectra of SGAs and steroidal glycoalkaloid aglycones (SGAAs) are very simple and similar (Kuronen et al., 1999). They lack chromatographic groups in the common operating range of UV spectrophotometry and absorb only at the low wavelength end of the UV spectrum. This means that they have low UV sensitivity and can be detected and identified by diode array detection (DAD) UV only when present in relatively high amounts (5-10 ng/injection) (Cherkaoui et al., 2001; Crabbe and Fryer, 1980; Kuronen et al., 1999).

Steroidal glycoalkaloids are of great interest from both ecological and human health aspects. They may also play important roles in the plant's efforts to protect itself against herbivores and microbial pathogens. They have been described as being antibiotic, antifungal, antimicrobial, and antiviral (Lee et al., 2007). In probably the majority of plants which elaborate glycoalkaloids, the main aglycone is solasodine (Cherkaoui et al., 2001). Solasodine (Figure 1) is a water insoluble steroidal alkaloid considered as potential raw material for steroid drug manufacture (Eltayeb et al., 1997; Jacob and Malpathak, 2005). It occurs in species of Solanum plants in the form of the water soluble 
triglycosides, solsonine and solamargine (Weissenberg, 2001) (Figure 1). Because of the great importance of solasodine in the pharmaceutical industry, there are many publications concerned with the search for solasodine glycosides in various plants (Kreft et al., 2000). For our study concerning the extraction and quantification of solasodine from the leaves of Solanum incanum, we required rapid and accurate analytical techniques for the determination of solasodine and related compounds.

It has been reported that only small structural differences in the steroid, or basic portion as well as the nature, number and order of attachments of sugar units in the carbohydrate moiety, influence the biological activity of the SGAs. Separation and determination of these structurally closely related compounds represent an enormous analytical challenge (Kuronen et al., 1999). A number of analytical methods have been reported for the determination of individual and total glycoalkaloids in Solanum plants (Carman et al., 1986; Eanes et al., 2008).

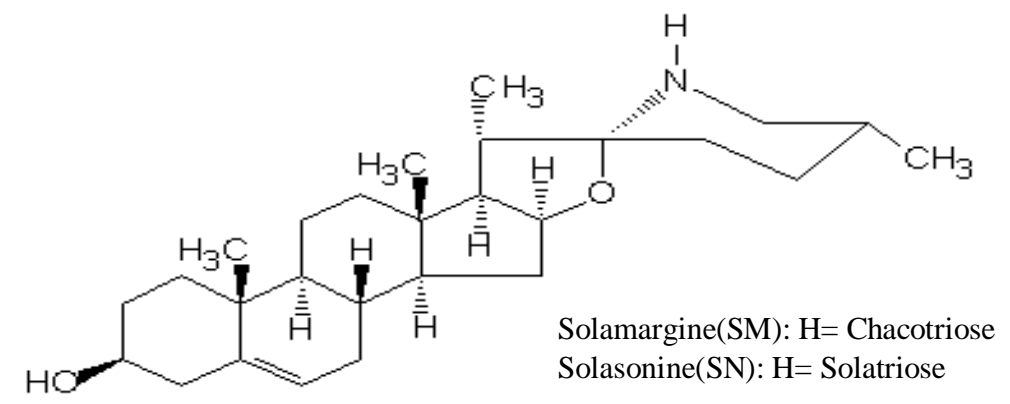

(a)

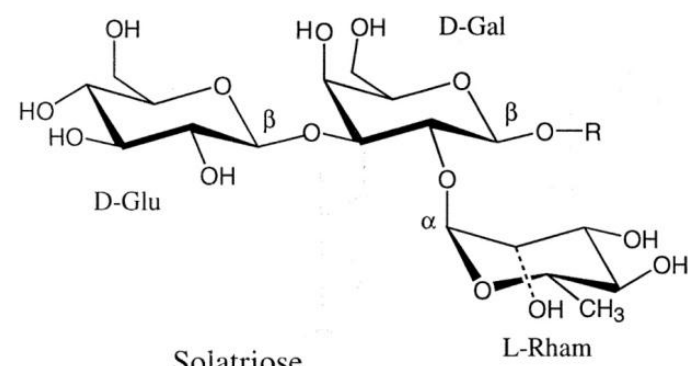

(b)

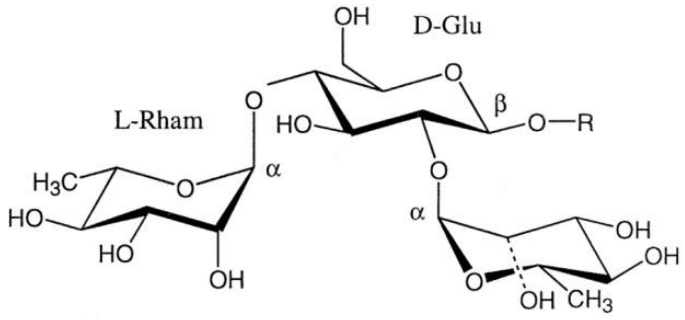

L-Rham

Chacotriose

Figure 1. Chemical structure of steroidal glycoalkaloids: a) solasodine b) sugar side chains.

A useful analysis method consists of three major steps: extraction of the alkaloids with aqueous or non-aqueous solvents, removal of interfering substances (impurities), and analysis. The methods in current use for the analysis of SGAs include: thin layer chromatography (TLC), gas chromatography (GC), high performance liquid chromatography (HPLC), mass spectrometry (MS), combined GC-MS, LC-MS, immunoassays, colorimetry, titrimetry or gravimetry (Carman et al., 1986; Eanes et al., 2008; Eltayeb et al., 1997; Friedman and Dao, 1992; Kreft et al., 2000; Trivedi and Pundarikakshudu, 2007). It must be pointed out that each method has its relative advantages and disadvantages, and no method is able to analyze the whole set of complex compounds in different types of samples. The methods of colorimetry, titrimetry or gravimetry are best suited to the determination of the total steroid base (Crabbe and Fryer, 1980). If further separation into aglycone and the various glycosides is required, then a chromatographic separation, either by paper or thin layer chromatography, is needed before the chemical analysis. This leads to a considerable increase in the errors involved and in the analysis time (Kuronen et al., 1999).

Gas chromatography has also been used for the analysis of steroidal alkaloids. However, these compounds have low volatility and are thermally unstable. Operation must be in all-glass systems at temperatures near the limit for packing materials. Only the aglycone forms can be analyzed directly; glycosides and sugars require permethylation or silylation (Crabbe and Fryer, 1980). High performance liquid chromatography (HPLC) should overcome the volatility and stability problems of gas chromatography. Although glycoalkaloids show limited absorption of ultraviolet (UV) light, HPLC separation followed by UV detection can still be considered a viable method, due to the relatively widespread availability of such instrumentation, its sensitivity, its suitability for separating non-volatile species or thermally fragile ones, and its adaptability to accurate quantitative determination (Dinan et al., 2001; Eanes et al., 2008). Since wavelengths less than $210 \mathrm{~nm}$ are required for solasodine and its glycosides, the range of solvents which can be used is limited and the use of solvent gradient programming is unlikely to be appropriate (Crabbe and Fryer, 1980; Kuronen et al., 1999). The main aim of this study 
was to investigate the effect of chromatographic conditions on the HPLC behavior of SGAs and SGAAs and to develop a simple method for quantification of SGAs and SGAAs, using commercial model compounds of solasodine and solamargine.

\section{Experiments}

\subsection{Chemicals and reagents}

Solasodine obtained from Sigma (St. Louis, MO, USA) and solamargine obtained from Glycomix Ltd (UK) were used as reference compounds. Distilled water was deionized before use. HPLC-grade acetonitrile and methanol were obtained from Sigma Aldrich (Germany). Ammonium dihydrogen phosphate from BDH Ltd (Poole, England) was prepared in water at different concentrations and $\mathrm{pHs}$ as buffers and these solutions were filtered through a $0.45 \mu \mathrm{m}$ membrane filter before use (Whatman, Germany). Orthophosphoric acid (85\%) was from BDH Ltd (Poole, England).

\subsection{Preparation of standards}

The glycoalkaloid standard solutions were prepared by dissolving solasodine and solamargine $(400 \mu \mathrm{g} / \mathrm{ml}) \mathrm{in}$ methanol. The stock solutions were stored at $4{ }^{\circ} \mathrm{C}$. HPLC working standards were prepared by diluting the stock solutions in methanol.

\subsection{HPLC procedure}

A Waters Associates (Milford, MA) HPLC system comprised of a 626 pump, a 996 photodiode array (PDA) detector and a 717 plus autosampler was used. The column was a symmetry $C_{18} 5 \mu \mathrm{m}(4.6 \times 150 \mathrm{~mm})$ from Waters.

The solvent flow rate was $1 \mathrm{ml} / \mathrm{min}$ and the absorption was measured at 200-205 $\mathrm{nm}$. Under isocratic conditions, the mobile phase consisted of a methanol: ammonium dihydrogen phosphate buffer at different ratios and different $\mathrm{pH}$ values. All solvent ratios are given on a volume basis. The mobile phase was filtered through a $0.45 \mu \mathrm{m}$ filter and degassed before use. The injector loop was $5 \mu$ l. HPLC conditions were according to those reported by Crabbe and Fryer (1980), with some modifications.

\section{Results}

The aim of this work was to find chromatographic conditions suitable for the detection and quantification of solasodine and solamargine. The degree of separation for solasodine and solamargine was very strongly dependent on chromatographic conditions.

\subsection{Effect of solvent/buffer ratio}

Methanol $(\mathrm{MeOH})$ was the organic portion of the mobile phase, whereas the buffer was ammonium dihydrogen phosphate $\left(\mathrm{AH}_{2} \mathrm{P}\right) 100 \mathrm{mM}$, acidified to $\mathrm{pH} 2.5$ and $\mathrm{pH} 3.5$ with $85 \%$ orthophosphoric acid as, according to Eanes et al. (2008), it produced better separations of the SGAs and SGAAs under isocratic conditions. Figures 2a-d and 3a-d show the chromatograms that were obtained when using a $\mathrm{MeOH} / \mathrm{AH}_{2} \mathrm{P}(100 \mathrm{mM} / \mathrm{pH} 2.5$ for solasodine and $100 \mathrm{mM} / \mathrm{pH} 3.5$ for solamargine) mobile phase system at different ratios. It can be seen that the solasodine (aglycone) eluted much faster (retention time (RT) 2.9 minutes) when the percentage of the methanol in the mobile phase was increased to $80 \%$ (Figure 2d). Under these conditions, the solamargine (SGAs) eluted too quickly to be detected (results are not shown), requiring that the methanol percentage be decreased. However, decreasing the percentage of the methanol to $60 \%$ and $55 \%$ resulted in an increase of the run times ( 7.9 minutes for solasodine and 7.7 minutes for solamargine respectively), and in a broadening of solasodine and solamargine bands (Figures 2a and 3a).

When different ratios of acetonitrile $(\mathrm{ACN}) / \mathrm{ammonium}$ dihydrogen phosphate $\left(\mathrm{AH}_{2} \mathrm{P}\right)(\mathrm{pH} 2.5 / 100 \mathrm{mM})$ were used, solasodine and solamargine were either not detected at all, eluted as very broad peaks or could not be reproduced after several injections (results are not shown). These results show that the optimal isocratic solvent conditions were $70 \%$ methanol:30 \% $\mathrm{AH}_{2} \mathrm{P}(\mathrm{pH} 2.5 / 100 \mathrm{mM})$ buffer for the separation of solasodine, but $65 \%$ methanol:35\% $\mathrm{AH}_{2} \mathrm{P}$ buffer $(\mathrm{pH} 3.5 / 100 \mathrm{mM})$ for the separation of solamargine.

\subsection{Effect of $\mathrm{pH}$ of the buffer}

A change in $\mathrm{pH}$ is an effective way to vary separation selectively for ionic samples. Figures $4 \mathrm{a}-\mathrm{d}$ and $5 \mathrm{a}-\mathrm{d}$ illustrate the separation of solasodine and solamargine at different $\mathrm{pH}$ values when using an ammonium dihydrogen phosphate buffer. As the $\mathrm{pH}$ of the buffer was decreased, solasodine was eluted earlier, peaks were sharper and the peak shapes improved compared to those at higher $\mathrm{pH}$. Figure $4 \mathrm{~d}$ shows that at $\mathrm{pH} 5.5$ separation of solasodine worsened and was delayed (RT 10 minutes).

The chromatograms in Figure 5a-d show that varying pH from 2.5 (a) to 3.5 (b), 4.5(c), and 5.5(d) did little to improve the separation of solamargine. Overall, lowering the $\mathrm{pH}$ of the mobile phase decreased the retention time of solamargine. The peaks were narrower with buffer $\mathrm{pH} 2.5$ for solasodine and $\mathrm{pH} 3.5$ for solamargine. 


\subsection{Effect of molarity of the buffer}

Solasodine was eluted as broad and tailing peaks when no buffer was used (Figure 6a, b) as compared to the case when a $100 \mathrm{mM} \mathrm{AH}_{2} \mathrm{P}$ buffer ( $\mathrm{pH}$ 2.5) was used. When the mobile phase was buffered, tailing of the recorded peaks was greatly reduced and peaks were eluted earlier (Figure 2b-d).

Increasing the molarity of the $\mathrm{AH}_{2} \mathrm{P}(\mathrm{pH} 3.5)$ from $20 \mathrm{mM}$ to $100 \mathrm{mM}$ increased retention time of solamargine but improved the resolution (Figure $7 \mathrm{a}, \mathrm{b}$ ). The use of a buffer helped to reduce the tailing in both solasodine and solamargine. Hence an ammonium dihydrogen phosphate buffer $(100 \mathrm{mM})$ was chosen as it produced better separation of both solasodine and solamargine.

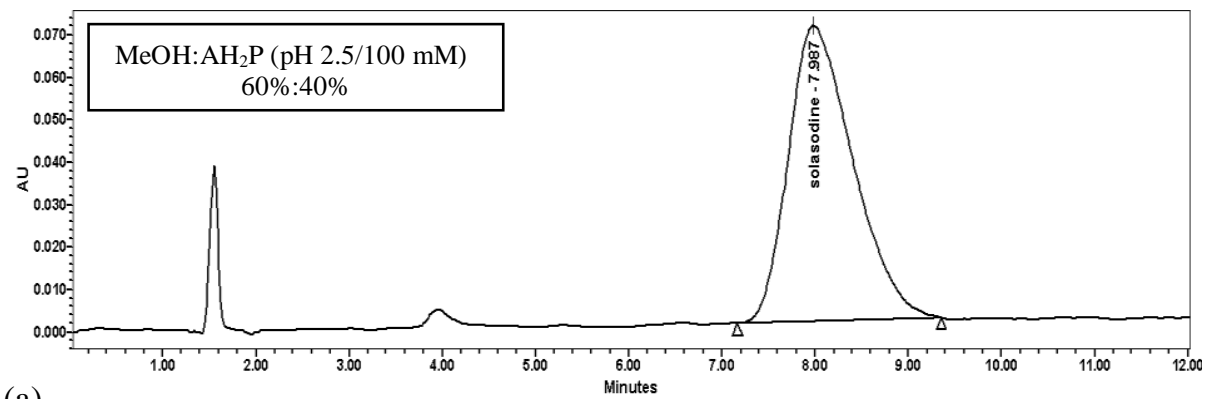

(a)

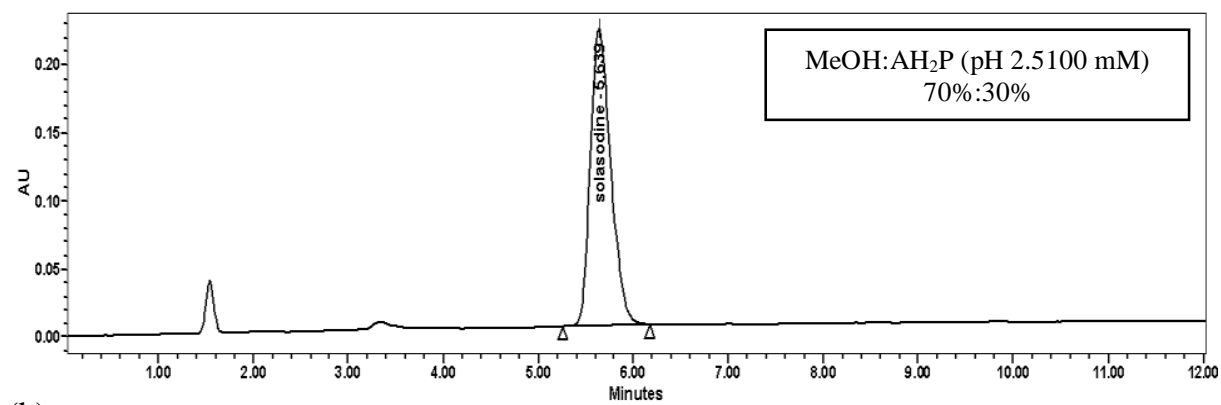

(b)

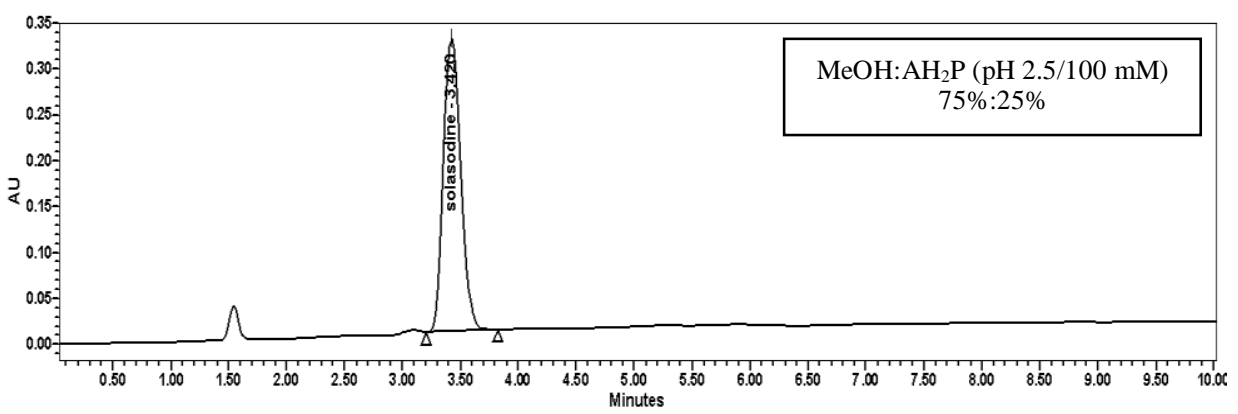

(c)

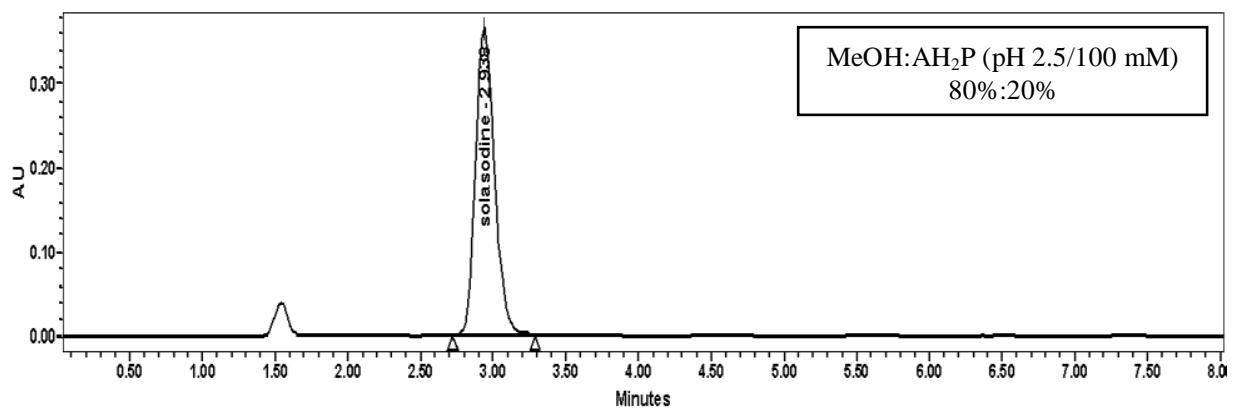

(d)

Figure 2. Effect of the percentage of the organic solvent on the separation of solasodine at temperature $25^{\circ} \mathrm{C}$ and flow rate $1 \mathrm{ml} / \mathrm{min}$. 


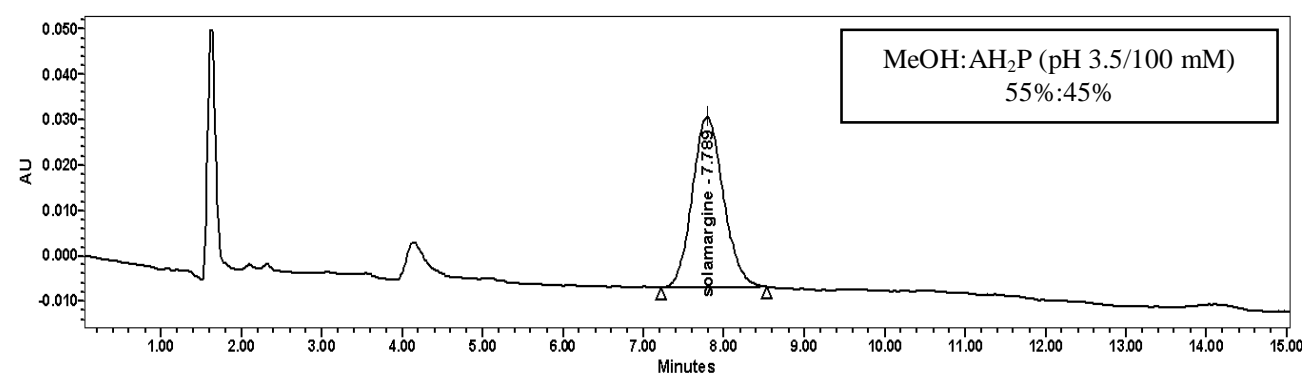

(a)

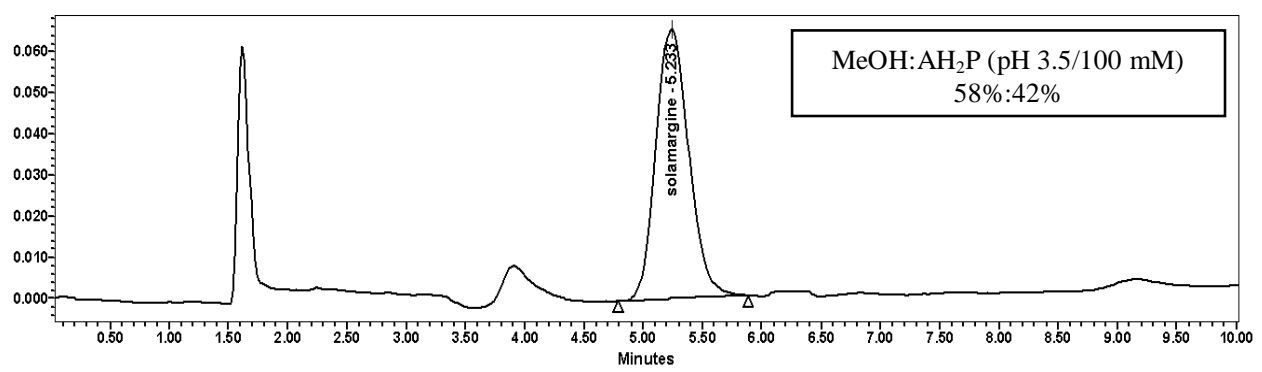

(b)

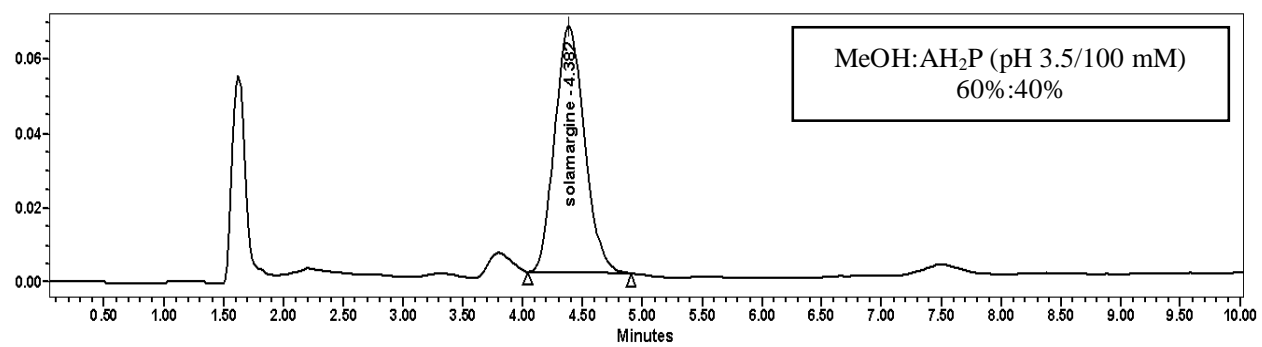

(c)

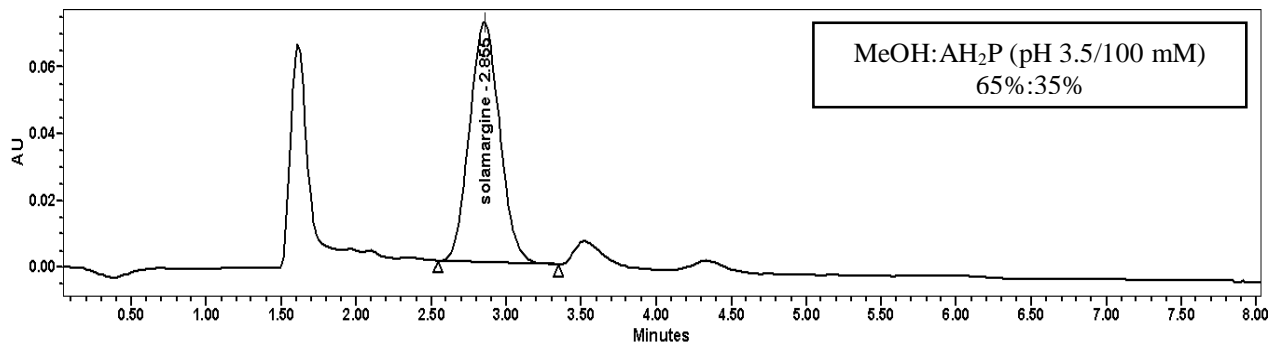

(d)

Figure 3. Effect of the percentage of the organic solvent on the separation of solamargine at temperature $25^{\circ} \mathrm{C}$ and flow rate $1 \mathrm{ml} / \mathrm{min}$.

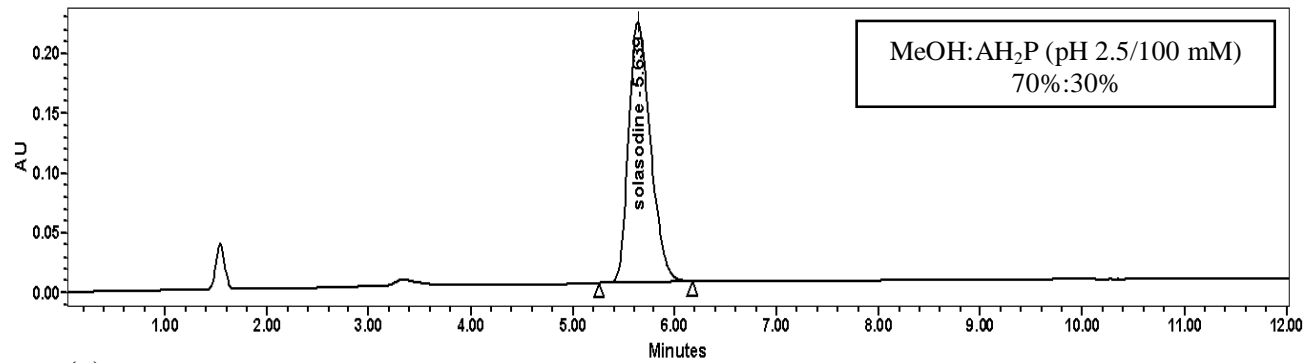

(a) 
SANA S. AL-SINANI and ELSADIG A. ELTAYEB

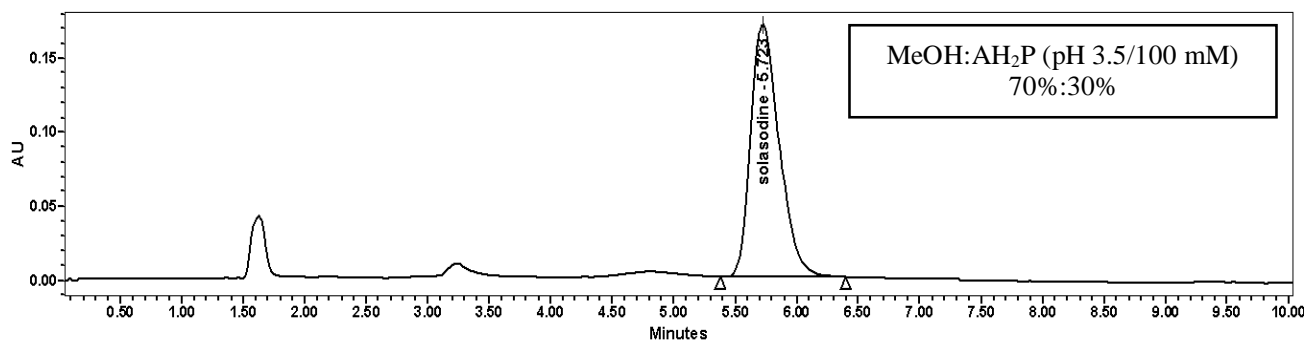

(b)

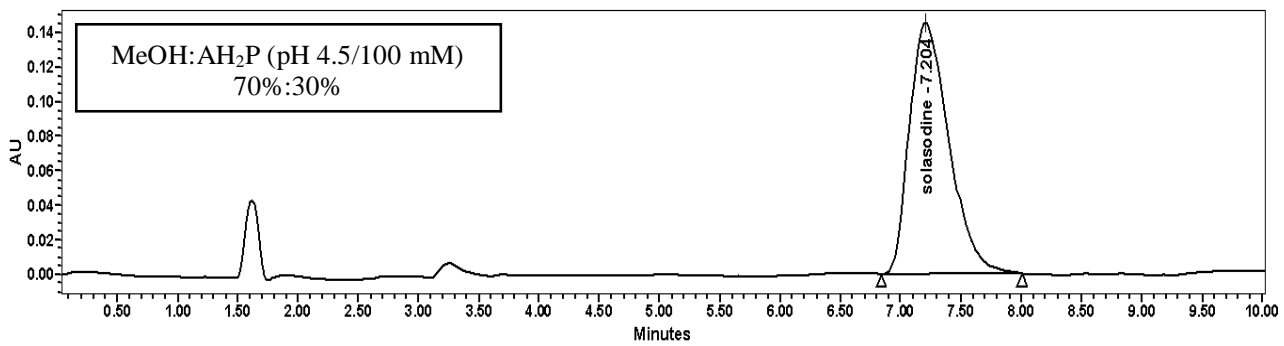

(c)

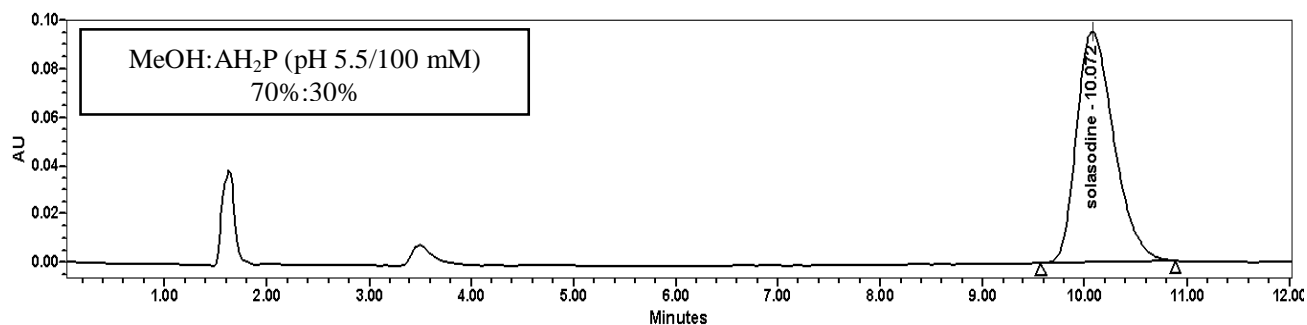

(d)

Figure 4. Effect of the $\mathrm{pH}$ of the buffer on the separation of solasodine at temperature $25^{\circ} \mathrm{C}$ and flow rate $1 \mathrm{ml} / \mathrm{min}$.

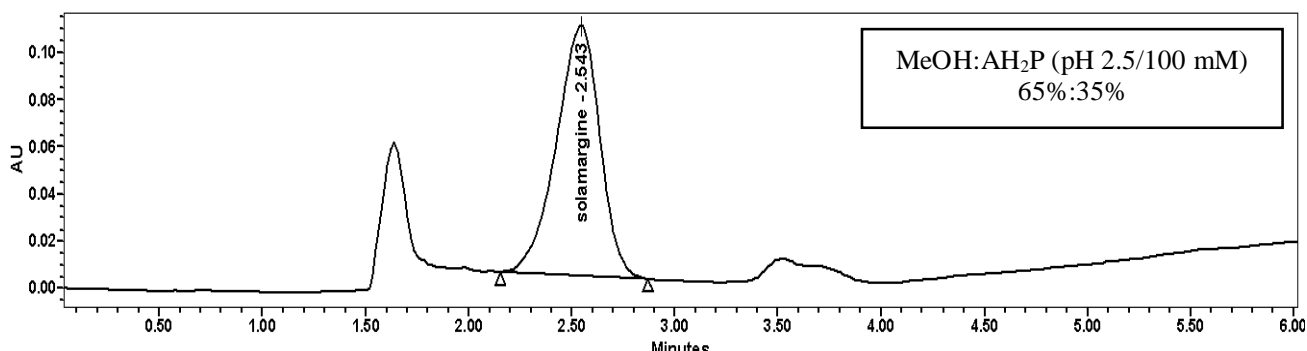

(a)

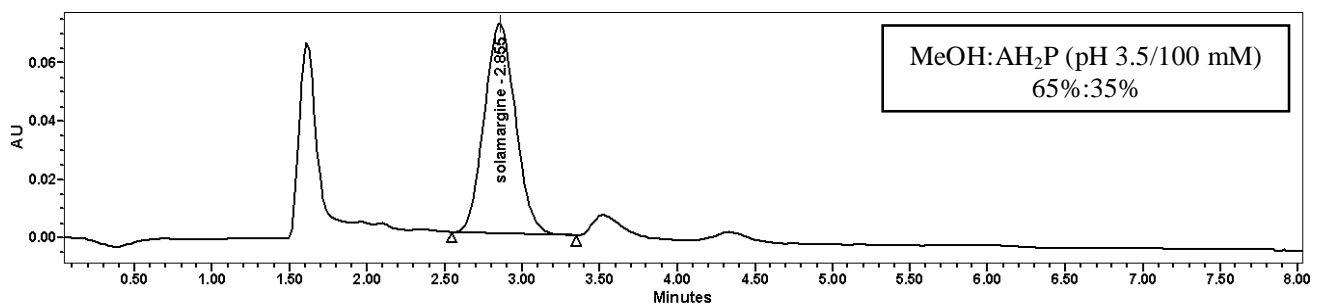

(b) 


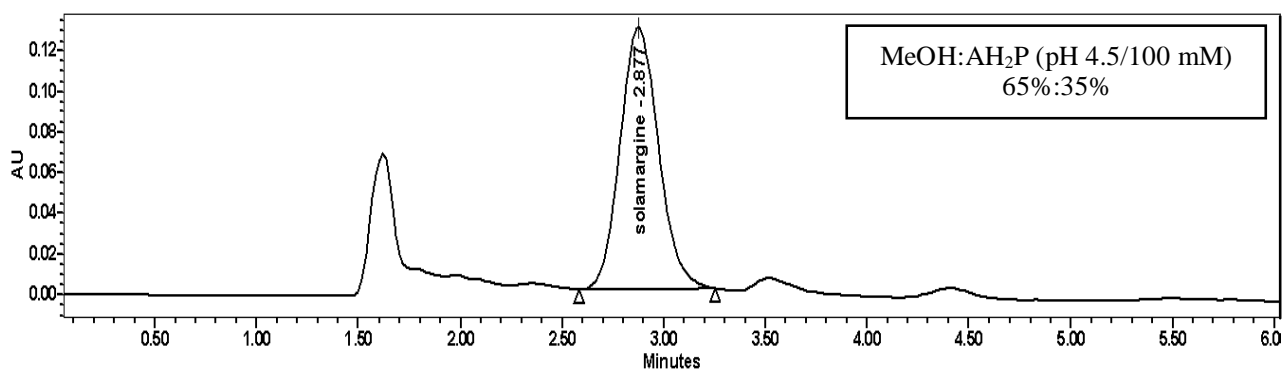

(c)

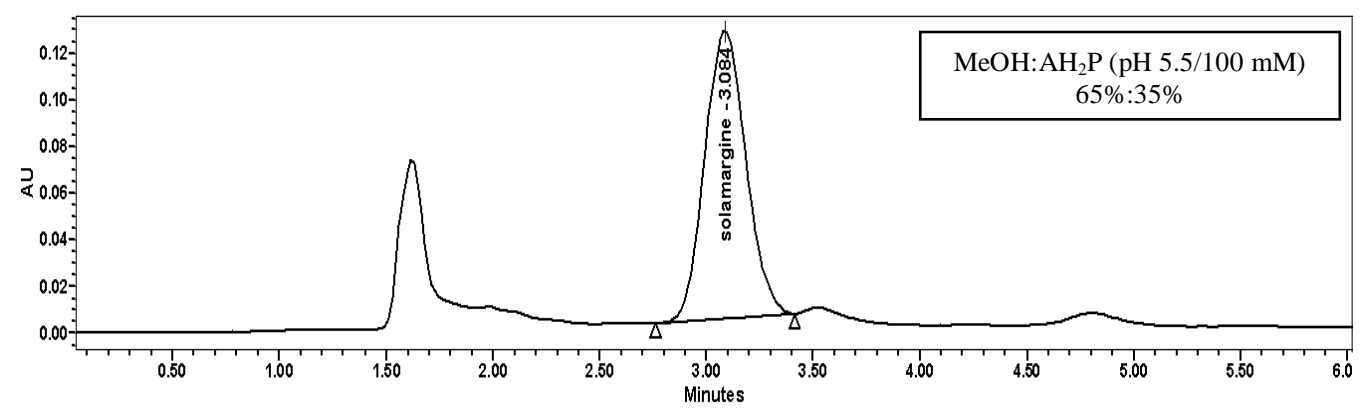

(d)

Figure 5. Effect of the $\mathrm{pH}$ of the buffer on the separation of solamargine at temperature $25{ }^{\circ} \mathrm{C}$ and flow rate $1 \mathrm{ml} / \mathrm{min}$.

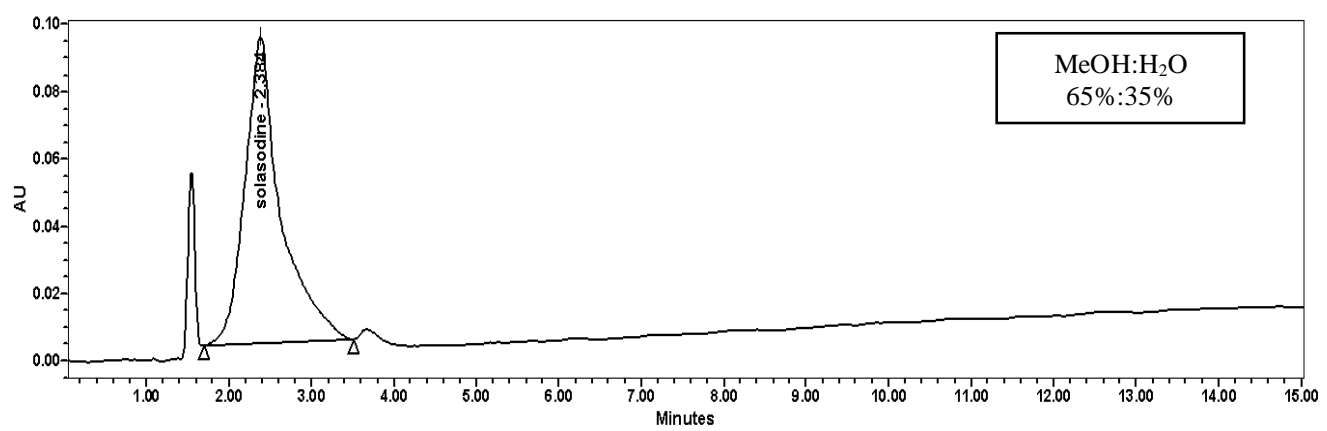

(a)

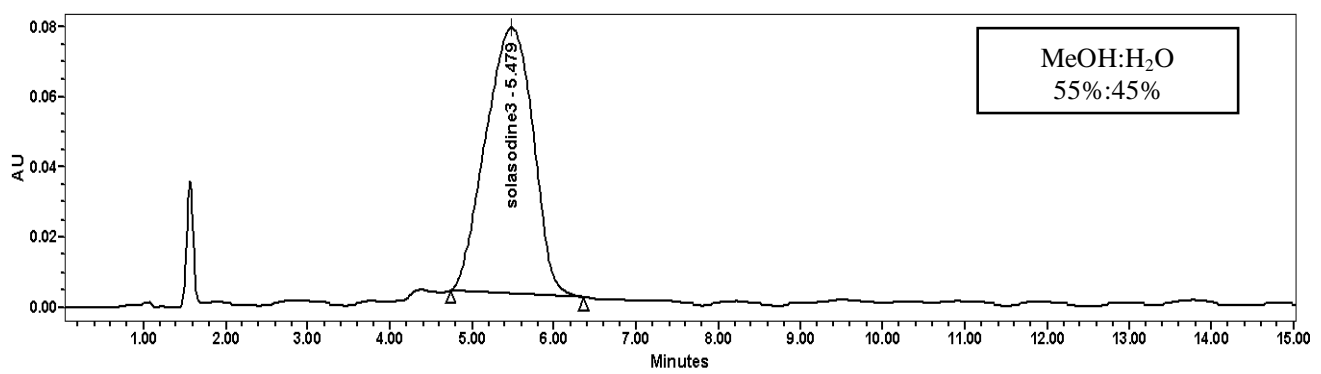

(b)

Figure 6. Effect of using water instead of buffer on separation of solasodine at temperature $25^{\circ} \mathrm{C}$ and flow rate 1 $\mathrm{ml} / \mathrm{min}$. 


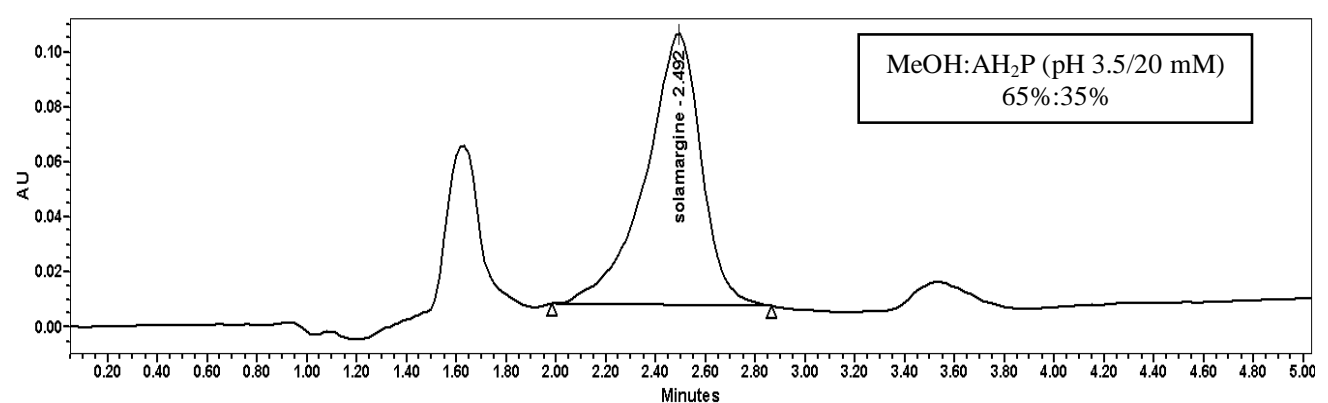

(a)
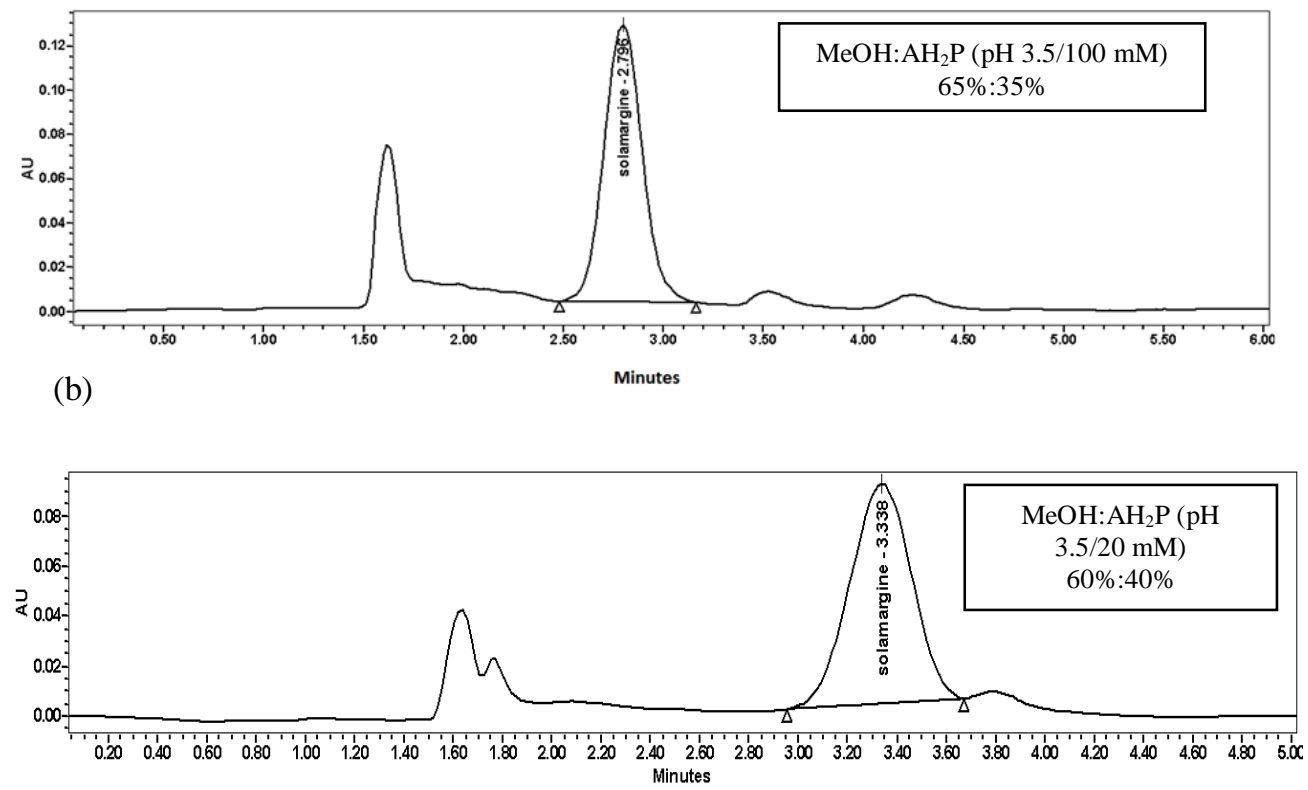

(c)

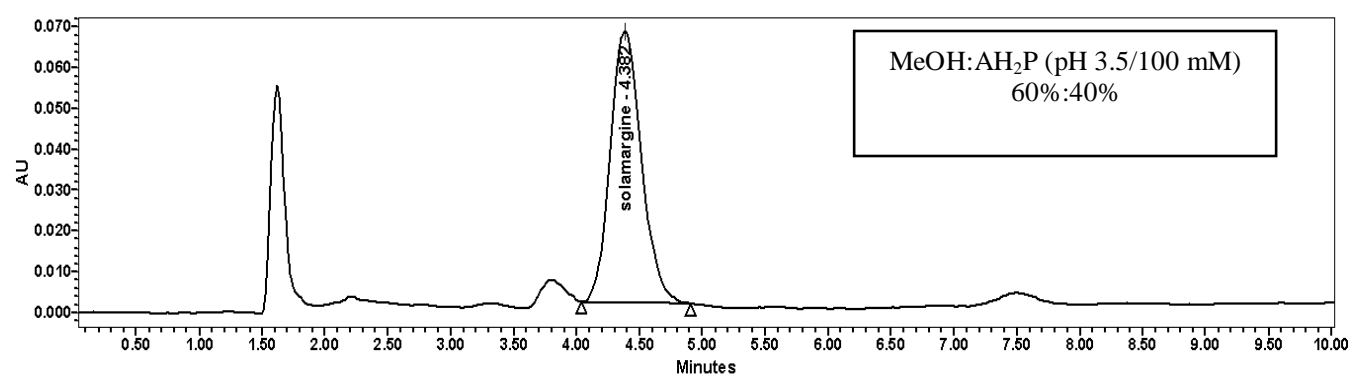

(d)

Figure 7: Effect of buffer concentration on the separation of solamargine at different percentages at temperature $25^{\circ} \mathrm{C}$ and flow rate $1 \mathrm{ml} / \mathrm{min}$.

\section{Calibration Results}

Calibration was performed by injecting solasodine and solamargine standards at levels ranging from 6-800 $\mu \mathrm{g} / \mathrm{ml}$ for solasodine and from $25-200 \mu \mathrm{g} / \mathrm{ml}$ for solamargine. The calibration plots for solasodine and solamargine are shown in Figures 8 and 9. Good linearity of response was found for both solasodine and solamargine, with correlation coefficients greater than 0.9950 . 


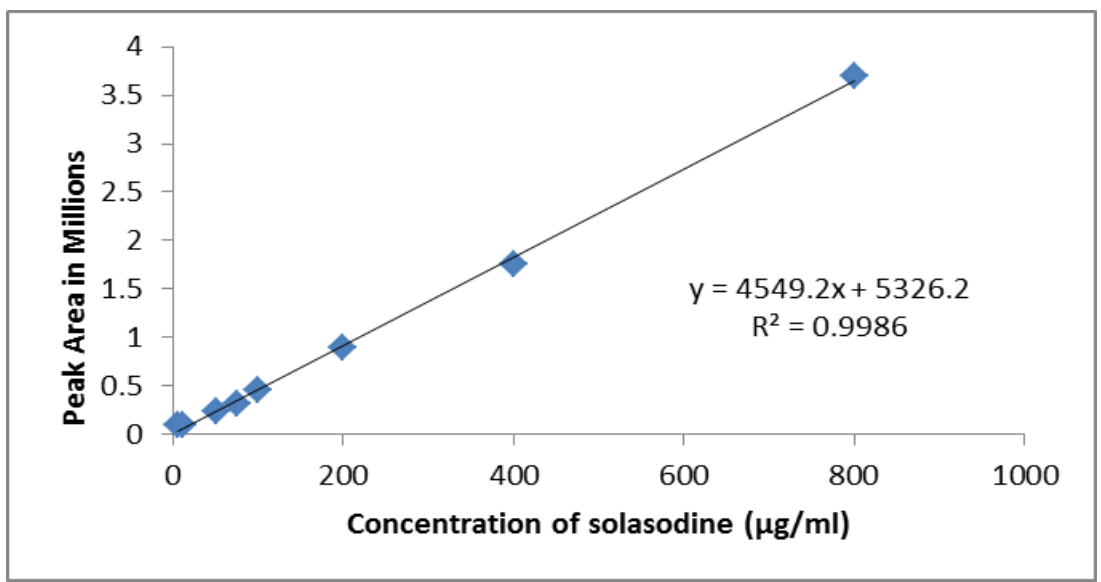

Figure 8. Calibration plot for solasodine in the concentration range of $6-800 \mu \mathrm{g} / \mathrm{ml}$.

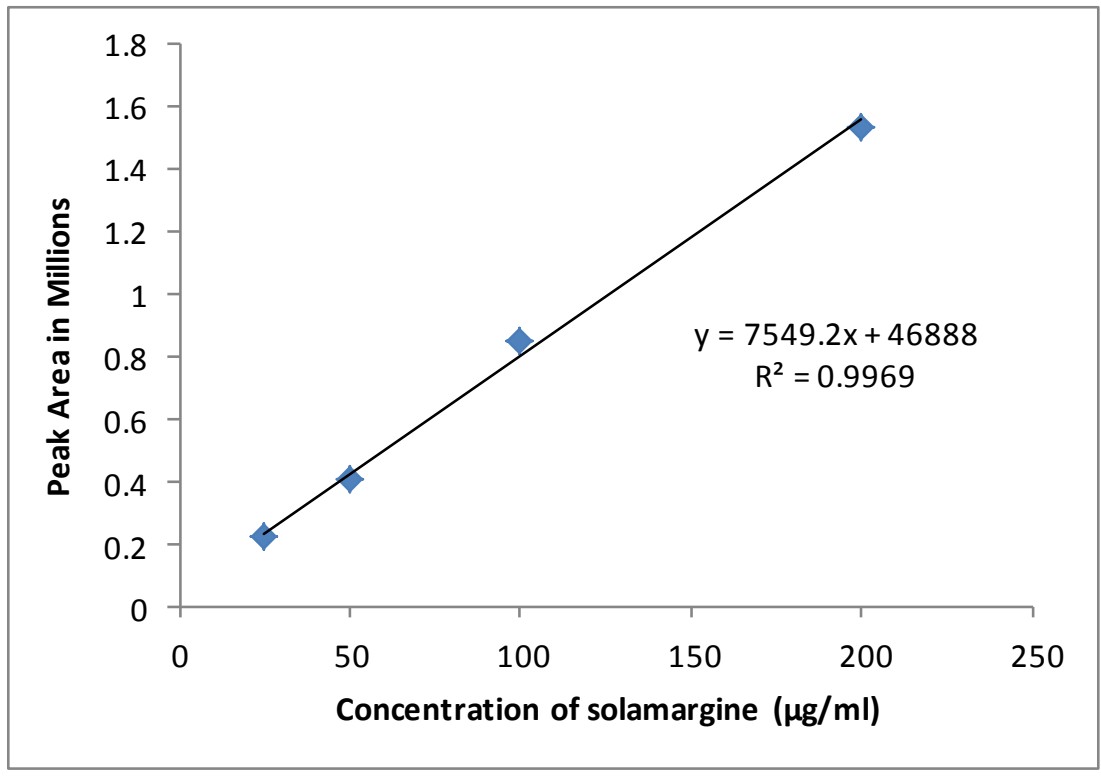

Figure 9. Calibration plot for solamargine in the concentration range of $25-200 \mu \mathrm{g} / \mathrm{ml}$.

\section{Discussion}

The chromatographic properties of SGAs (solamargine) and their aglycones (solasodine) were evaluated by monitoring their elution characteristics in high performance liquid chromatography (HPLC). The results show the importance of a careful choice of the chromatographic conditions for successful LC separation of these compounds. The HPLC procedure for quantification of solasodine and solamargine was developed using methanol for the mobile phase. Commercial solasodine and solamargine were used as external standards.

Solasodine is relatively non polar, and virtually insoluble in water but soluble in alcohols and nonpolar solvents such as chloroform and benzene. Solamargine is less polar, but, because of the presence of sugars in the glycosides, these compounds have a much greater polarity, which increases as more sugars are attached (Crabbe and Fryer, 1980). Because of the low polarity of the molecules to be separated, reversed phase chromatography was chosen by using a Waters Association (Milford, USA) system with $\mathrm{C}_{18}$ packing (with methanol-buffer, methanol-water, or acetonirilebuffer, acetonitrile-water).

In an attempt to detect and quantify solasodine and solamargine in two separate chromatographic runs with isocratic elution, a methanol/ammonium dihydrogen phosphate buffer $(\mathrm{pH} 2.5 / 100 \mathrm{mM})$ solvent system was evaluated initially, since this was found to be the best mobile phase system eluting reproducibly both the SGAs and SGAAs (Crabbe and Fryer, 1980; Eanes et al., 2008).

This study shows that the most appropriate isocratic solvent conditions for the separation of solasodine were $70 \%$ methanol: $30 \% \mathrm{AH}_{2} \mathrm{P}\left(\mathrm{pH} 2.5 / 100 \mathrm{mM}\right.$ ) buffer, but that $65 \%$ methanol: $35 \% \mathrm{AH}_{2} \mathrm{P}$ buffer $(\mathrm{pH} 3.5 / 100 \mathrm{mM})$ was necessary for the elution of solamargine. Furthermore, solasodine and solamargine could not be detected at all when different ratios of $\mathrm{ACN}$ : $\mathrm{AH}_{2} \mathrm{P}$ buffer $(100 \mathrm{mM} / \mathrm{pH} 2.5)$ were used: under these conditions it eluted as broad peaks or could not be reproduced after several injections. The latter results are not consistent with the results of Eanes et al., 
(2008), which used ACN as the organic portion of the mobile phase and a $\mathrm{C}_{18}$ Nucleosil column. They showed that the best set of isocratic conditions for the separation of solasodine was $60 \% \mathrm{ACN}: 40 \% \mathrm{AH}_{2} \mathrm{P}$ buffer $(100 \mathrm{mM} / \mathrm{pH} 2.5)$, and for solamargine it was 30\% ACN:70\% $\mathrm{AH}_{2} \mathrm{P}$ buffer $(100 \mathrm{mM} / \mathrm{pH} 2.5)$. Most of the previous studies developed a HPLC procedure for quantification of solamargine using ACN. Kuronen et al.'s (1999) experiments revealed that an ACN:25 mM TEAP buffer ( $\mathrm{pH}$ 3.0) was the best solvent system eluting reproducibly both SGAs and SGAAs under both isocratic and gradient elution conditions from silica-based $\mathrm{C}_{18}$ columns. The optimal isocratic solvent conditions were $25-30 \%$ ACN in a triethylammonium phosphate (TEAP) buffer ( $\mathrm{pH}$ 3.0) for the separation of SGAs, but for the separation of SGAAs 40-60\% ACN in a TEAP buffer (pH 3.0) was necessary (Kuronen et al., 1999). These results are in agreement with results previously reported by Lee et al. (2007) who obtained separation of solanine and solasodine with a reverse-phase column (Cosmosil 5C 18 -AR-II, $250 \mathrm{~mm} \times 4.6 \mathrm{~mm}$ ) eluting at a flow rate of $1 \mathrm{ml} / \mathrm{min}$ also using ACN: TEAP buffer but with a linear solvent gradient elution from 20 to $70 \%$ ACN in 20 mins.

It must be pointed out that some reported studies on the analysis of SGAAs and SGAs (Eanes et al., 2008; Kuronen et al., 1999) assumed that because the weak solvent of the mobile phase was water, acidified to $\mathrm{pH} 3.0 \mathrm{with}$ $85 \%$ orthophosphoric acid, both SGAs and SGAAs eluted as broad and tailing peaks at varying retention times or even not at all. However, they found that the use of a buffer helped to reduce tailing of peaks in both solasodine and solamargine and the retention times decreased with decreasing the $\mathrm{pH}$ of the buffer. These results are consistent with the results of this study. By using a low pH mobile phase, both basic functional groups of glycoalkaloids and acidic silanol groups on the silica support are fully protonated minimizing ionic interactions between them and providing more reproducible separations (Kuronen et al., 1999).

\section{References}

CARMAN, A.S., KUAN, S.S., WARE, G.M., FRANCIS, O.J. and KIRSCHENHENHEUTER, G.P. 1986. Rapid High-Performance Liquid Chromatographic Determination of the Potato Glycoalkaloids Alpha.-Solanine and Alpha.-Chaconine. J. Agricultural and Food Chemistry, 34(2): 279-282.

CHERKAOUI, S., BEKKOUCHE, K., CHRISTEN, P. and VEUTHEY, J.L. 2001. Non-Aqueous Capillary Electrophoresis with Diode Array and Electrospray Mass Spectrometric Detection for the Analysis of Selected Steroidal Alkaloids in Plant Extracts. J. Chromatography A, 922(1-2): 321-328.

CRABBE, P.G. and FRYER, C. 1980. Rapid Quantitative Analysis of Solasodine, Solasodine Glycosides and Solasodiene by High-Pressure Liquid Chromatography. J. Chromatography A, 187(1): 87-100.

DINAN, L., HARMATHA, J. and LAFONT, R. 2001. Chromatographic Procedures for the Isolation of Plant Steroids. J. of Chromatography A. 935(1-2): 105-123.

EANES, R.C., TEK, N., KIRSORY, O., FRARY, A., DOGANLAR, S. and ALMEIDA, A.E. 2008. Development of Practical HPLC Methods for the Separation and Determination of Eggplant Steroidal Glycoalkaloids and their Aglycones. J. Liquid Chromatography \& Related Technologies. 31(7): 984-1000.

ELTAYEB, E.A., AL-ANSARI, A.S. and RODDICK, J.G. 1997. Changes in the Steroidal Alkaloid Solasodine During Development of Solanum Nigrum and Solanum Incanum. Phytochemistry, 46(3): 489-494.

FRIEDMAN, M. and DAO, L. 1992. Distribution of Glycoalkaloids in Potato Plants and Commercial Potato Products. J. Agricultural and Food Chemistry, 40(3): 419-423.

JACOB, A. and MALPATHAK, N. 2005. Plantlet Regeneration Enhances Solasodine Productivity in Hairy Root Cultures of \&lt;i\&gt; Solanum Khasianum \&lt;/i\&gt; Clarke. In Vitro Cellular \& Developmental Biology - Plant, 41(3): 291-295.

KREFT, S., ZEL, J., PUKL, M., UMEK, A. and STRUKELJ, B. 2000. Non-Aqueous Capillary Electrophoresis for the Simultaneous Analysis of Solasodine and Solasonine. Phytochemical Analysis, 11(1): 37-40.

KURONEN, P., VÄÄNÄNEN, T. and PEHU, E. 1999. Reversed-Phase Liquid Chromatographic Separation and Simultaneous Profiling of Steroidal Glycoalkaloids and their Aglycones. J. of Chromatography A, 863(1): p. 2535.

LEE, M.-H., CHENG, J.-J., LIN, C.-Y., CHEN, Y.-J. and LU, M.-K. 2007. Precursor-Feeding Strategy for the Production of Solanine, Solanidine and Solasodine by a Cell Culture of Solanum Lyratum. Process Biochemistry, 42(5): 899-903.

TRIVEDI, P. and PUNDARIKAKSHUDU, K. 2007. Novel TLC Densitometric Method for Quantification of Solasodine in Various \&lt;i\&gt; Solanum \&lt;i\&gt; Species, Market Samples and Formulations. Chromatographia, 65(3): 239-243.

WEISSENBERG, M. 2001. Isolation of Solasodine and other Steroidal Alkaloids and Sapogenins by Direct Hydrolysis-Extraction of Solanum Plants or Glycosides Therefrom. Phytochemistry, 58(3): 501-508. 